\title{
Phototherapy with PUVA: Versatility and efficacy in dermatoses
}

Tatiana Ferreira França ${ }^{1 *}$, Alessandra Vieira Diniz ${ }^{1}$, Ivanete lopes da Silva ${ }^{1}$, Rafaella Rêllo Pinto Coelho Carvalho ${ }^{1}$,

Vanessa Knauf Lopes ${ }^{1}$, Virgínia Vinha Zanuncio ${ }^{2}$

${ }^{1}$ Medical Student, Universidade Federal de Viçosa (UFV), Viçosa, MG, Brazil

${ }^{2}$ Assistant Professor of Dermatology, Department of Medicine and Nursing, UFV, Viçosa, MG, Brazil

Study conducted at Department of Medicine and Nursing, Universidade Federal de Viçosa (UFV), Viçosa, MG, Brazil

Article received: $11 / 4 / 2016$

Accepted for publication: $11 / 20 / 2016$

*Correspondence:

Address: Rua Feijó Bhering, 53, apto. 604

Viçosa, MG - Brazil

Postal code: 36570-000

tatif.franca@hotmail.com

\section{INTRODUCTION}

Phototherapy is used in the treatment of several dermatoses, many with high prevalence and chronic progression. ${ }^{1,2}$ Its classification is made according to the type of irradiation: ultraviolet A (UVA - between 320 and $400 \mathrm{~nm}$ wavelength) or ultraviolet B (UVB - between 290 and 320 $\mathrm{nm}) .{ }^{1}$ The range of UVB between $311-312 \mathrm{~nm}$ is called narrow-band.

The immunological basis of phototherapy is the activation of immune-modulating cascades caused by the absorption of UV rays by chromophores of the skin. Cell membrane and DNA damage ${ }^{3}$ occur due to photochemical reactions that have anti-inflammatory, immunosuppressive and antiproliferative effects. ${ }^{1,4}$

In order to determine the time and intensity of the sessions, a minimal erythematous dose (DEM), which is the minimum energy required to produce a uniform erythematous response within 24 hours, is calculated. Treatment is started with 75 to $90 \%$ of this dose. The energy is gradually increased to minimize adverse reactions and potentiate the treatment. ${ }^{1}$

PUVA treatment uses oral or topical psoralen followed by exposure to UVA irradiation. ${ }^{4}$ Psoralens are tricyclic furocoumarins derived from plants and activated by UV rays. ${ }^{4,5}$ The PUVA procedure with oral psoralens should be preceded by ophthalmologic evaluation and serum dosage of ALT, AST, gamma-glutamyltransferase (gamma GT), alkaline phosphatase, urea, creatinine, BHCG for women of childbearing age and antinuclear antibodies
(ANA) to detect potential sensitivity to R-UVA. Topical PUVA, in turn, is indicated primarily for patients with hepatic or gastrointestinal dysfunction, cataract, drug interactions, and for children. ${ }^{4,5}$

The absolute contraindications for PUVA are xeroderma pigmentosum, some genodermatoses, systemic lupus erythematosus, dermatomyositis, previous history of melanoma and trichothiodystrophy. Relative contraindications include age less than 10 years, previous or current history of non-melanoma skin cancer, immunosuppressive treatment, gestation, cataracts, severe hepatic dysfunction, and history of systemic malignant tumors. ${ }^{2}$

Adverse effects include increased risk of melanoma and non-melanoma skin cancer, gastrointestinal changes, erythema, burns and pruritus. There may be conjunctival changes and early cataract, justifying ocular protection with sunglasses for at least eight hours after ingestion of psoralens. As a late manifestation there is photoaging. ${ }^{1,4,6}$ Medical supervision and periodic laboratory evaluation are fundamental, as well as avoiding sun exposure with the use of physical and chemical barriers during treatment. ${ }^{2}$

This article aims to report three clinical cases, one of psoriasis, one of vitiligo and one of pityriasis alba, treated with PUVA with excellent response and, thus, show the diversity of dermatoses that can be treated with this therapeutic option. All the patients authorized in writing the use of their images as illustration of the cases by signing Free and Informed Consent Terms (FIC) forms. 


\section{Case reports}

\section{Case 1}

Female patient, 21 years old, student. Diagnosis of vitiligo since 2007 , treated in the past with topical and oral corticosteroids with no satisfactory response (Figure 1A). She denies any previous history of dermatoses or use of medications. We requested laboratory review and ophthalmologic evaluation as recommended, all within normal limits, before starting PUVA (8-methoxypsoralen 0.6 $\mathrm{mg} / \mathrm{kg}$ ) therapy twice weekly.

The patient progressed with xerosis and erythema in the lesions. We prescribe hydration and topical corticoid ( $0.1 \%$ mometasone furoate ointment) with good response and therefore without the need to discontinue treatment. After 44 sessions, the patient presented significant and satisfactory improvement of the lesions, with increased local pigmentation and improvement of achromic macules (Figure 1B). She is currently being treated with PUVA with gradual improvement of symptoms.

\section{Case 2}

Male patient, 48 years old, trader. Diagnosis of psoriasis 10 years ago (Figure $2 \mathrm{~A}$ ), with symptoms progressing. He has used unknown topical medications in the past. The patient denies other treatments, comorbidities, allergies and use of medications. PUVA therapy was indicated with 8-methoxypsoralen $0.6 \mathrm{mg} / \mathrm{kg}$ twice weekly. Laboratory review and ophthalmologic evaluation were requested before the start of treatment, in accordance with the protocol for phototherapy. After 14 sessions, the patient presented excellent results with significant improvement of psoriatic plaques (Figure 2B). Phototherapy was maintained as treatment.

\section{Case 3}

Male patient, aged 13 years, student, presenting hypochromic macules with indistinct margins and follicular papules located on the face (Figure 3A), compatible with pityriasis alba. He was being treated with hydrocortisone acetate $1 \%$ cream and moisturizer without satisfactory response. The patient denied having any comorbidities, other medications and allergies. Based on this information, we requested laboratory review and ophthalmologic evaluation, later recommending PUVA therapy with 8-methoxypsoralen $0.6 \mathrm{mg} / \mathrm{kg}$ twice weekly. After 21 sessions, the lesions showed complete improvement (Figure 3B).

\section{Discussion}

Biochemical exams and ophthalmologic evaluation were performed in all patients before PUVA treatment due to the

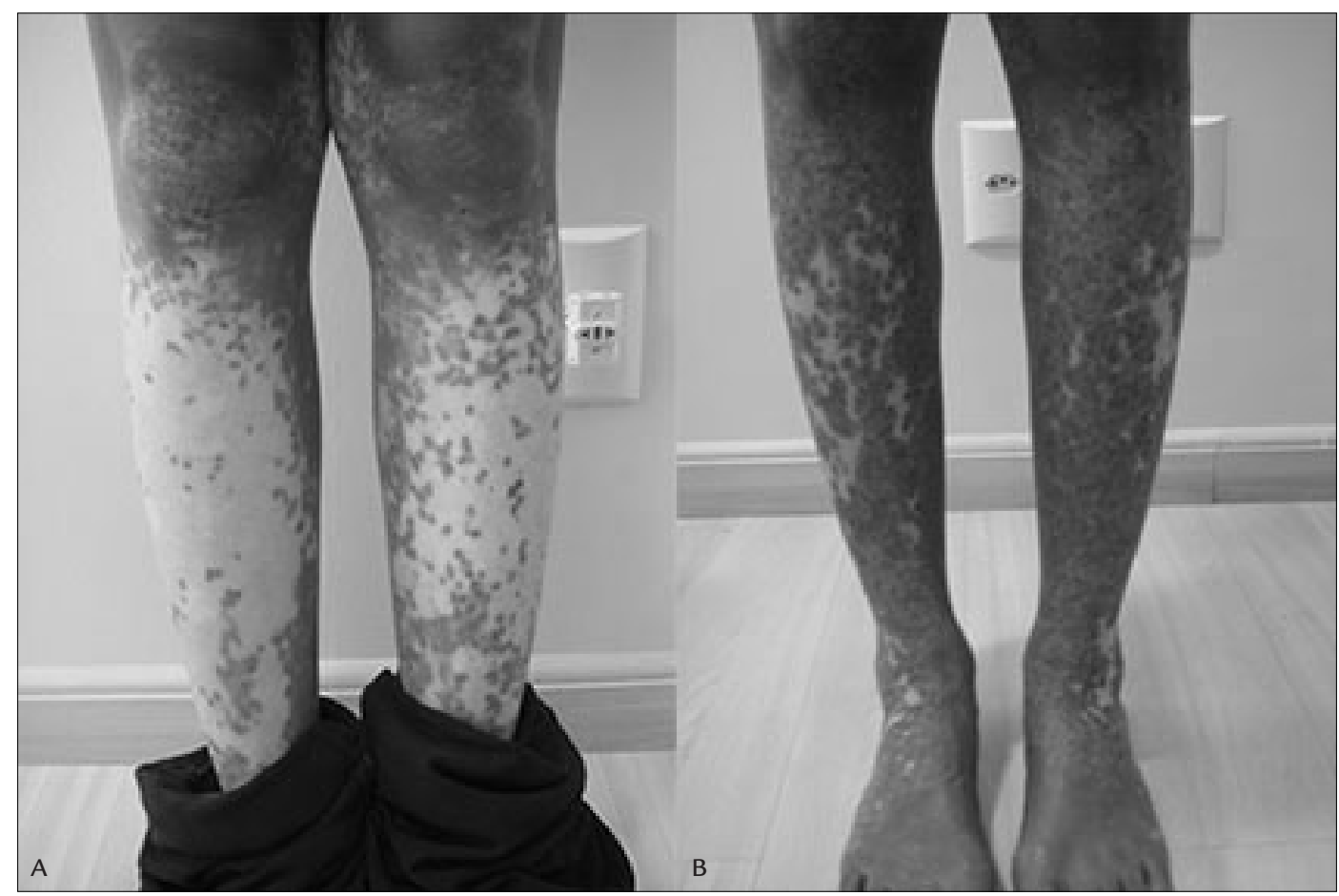

FIGURE 1 Achromic macules over the pre-tibial area before PUVA treatment, on the left. Increased pigmentation of vitiligo lesions after 44 PUVA sessions, on the right. 


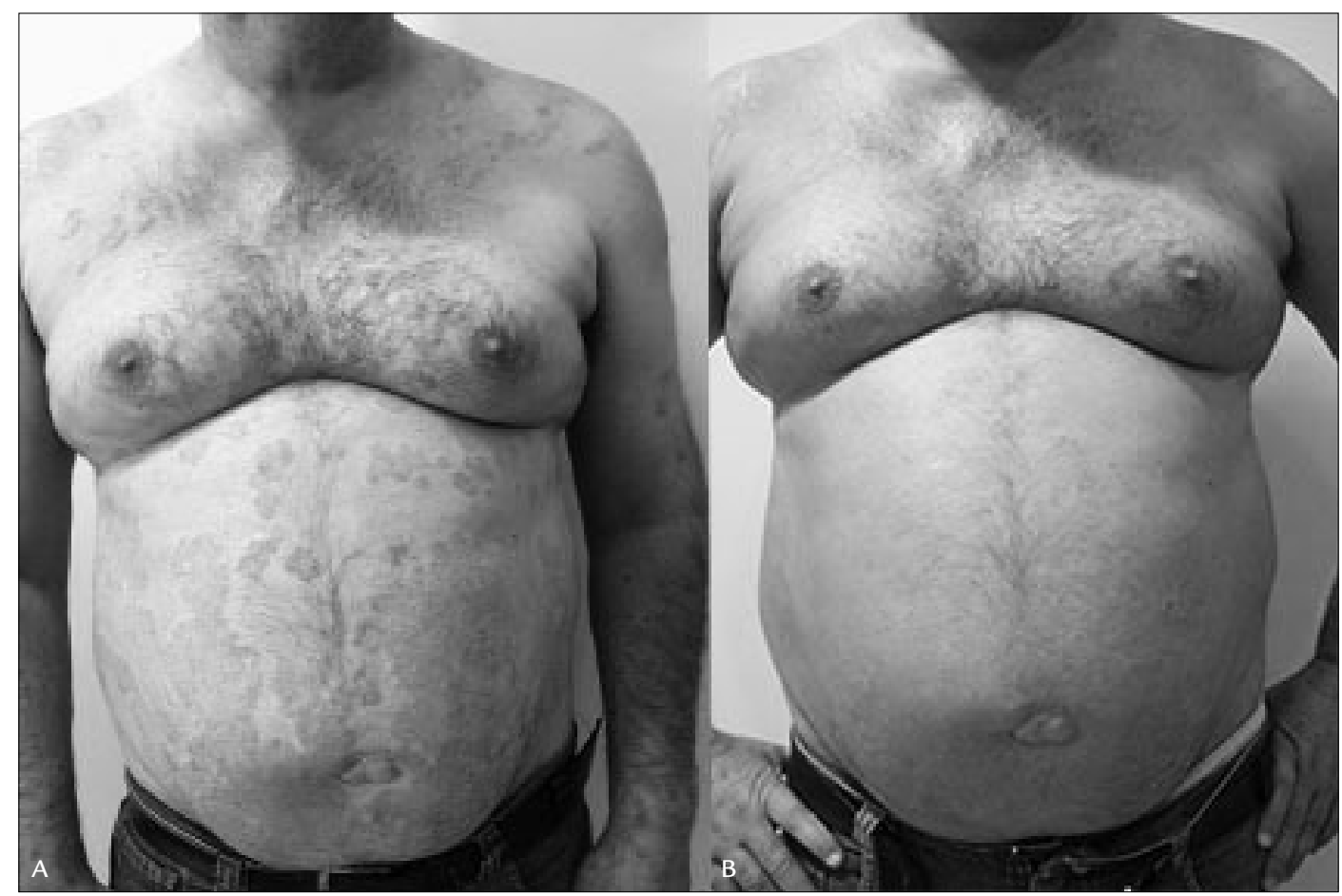

FIGURE 2 Extensive and confluent erythematous-scaling plaques, disseminated throughout the body prior to PUVA sessions on the left. Significant and satisfactory clinical improvement of psoriasis lesions after 14 sessions of PUVA, on the right.

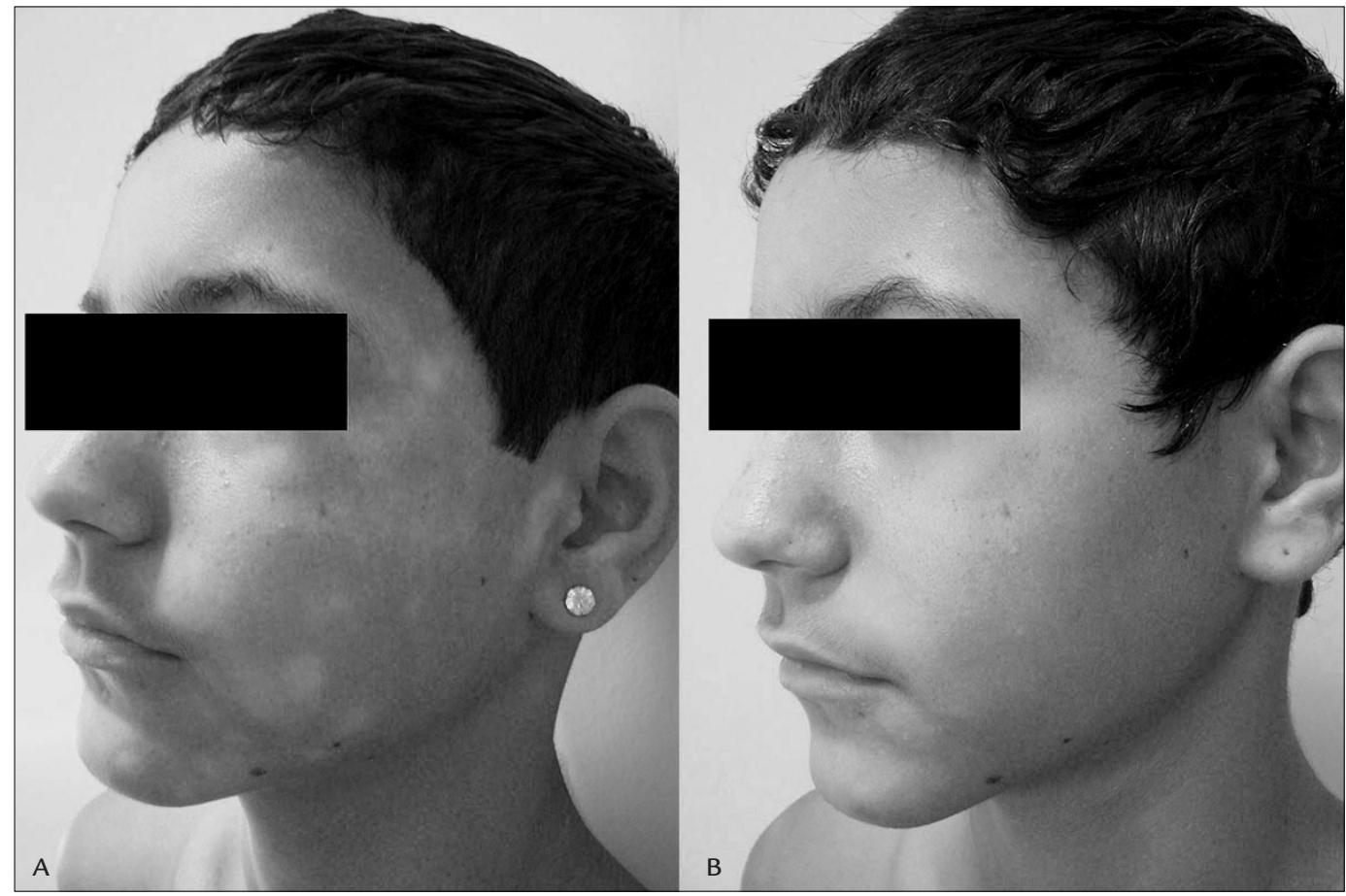

FIGURE 3 Hypochromic macules with poorly defined borders on the face compatible with pityriasis alba before PUVA, on the left. Satisfactory attenuation of pityriasis alba lesions after 21 PUVA sessions, on the right. 
possible side effects and contraindications, so that the procedure could be safely performed.

In all modalities of UVB phototherapy or PUVA, complementary therapies such as topical vitamin D analogues, corticosteroids and topical or oral retinoids may be associated for better control of psoriasis and other dermatoses. ${ }^{1,7,8}$

One of the main indications of phototherapy is the control of psoriasis. According to the Brazilian Consensus of Psoriasis 2012, any form of phototherapy can be used in this dermatosis. UVB is the first line for psoriasis, as it is safer and more effective. It can be used in pregnant women and children, and poses less risk of photoaging and ophthalmological involvement, since it does not require psoralens as adjuvants. ${ }^{7}$ On the other hand, PUVA is indicated as the best therapeutic option for extensive areas of involvement, thick psoriatic patches and patients with phototype III or greater. ${ }^{1,5,9,10}$ In case 2 , we chose PUVA because the patient had extensive psoriasis and thick plaques.

In vitiligo, repigmentation after treatment occurs due to migration of melanocytes from the hair follicles to the basal layer of the skin. ${ }^{11}$ Phototherapy stimulates melanogenesis and interferes with the inflammatory process of the dermatosis. ${ }^{1}$ In extensive vitiligo (as in the case presented) PUVA with oral psoralen is the best therapeutic option. Although many authors advocate UVB radiation as the safest method, others indicate it only when PUVA is contraindicated. ${ }^{1,2}$ We opted for PUVA with oral psoralen because of its effectiveness in extensive vitiligo.

The etiology of pityriasis alba is unknown but appears to be related to xerosis and atopic eczema. ${ }^{11}$ It mainly affects the face, back and outer side of the arms, sometimes posing a differential diagnosis with pityriasis versicolor. ${ }^{11,12}$ The treatment of choice are emollients, sun protection and the use of topical corticosteroids. Refractory cases can be treated with PUVA. ${ }^{13}$ The results of the sessions exceeded expectations with the disappearance of most of the lesions.

All three cases yielded excellent therapeutic results. Good tolerance to phototherapy should be emphasized without triggering relevant side effects. Thus, great psychosocial impact and self-esteem was obtained, with improvement in patients' quality of life.

\section{References}

1. Duarte IAG, Buense R, Kobata C. Fototerapia. An Bras Dermatol. 2006; 81(1):74-82

2. Cestari TF, Pessato S, Corrêa GP. Fototerapia: aplicações clínicas. An Bras Dermatol. 2007; 82(1):7-21.

3. Dunthie M.S, Kimber I, Norval M. The effects of ultraviolet radiation on the human immune system. Br J Dermatol. 1999; 140(6):995-1009.

4. Duarte IAG, Korkes KL, Amorim VAM, Kobata C, Buense R, Lazzarini R An evaluation of the treatment of parapsoriasis with phototherapy. An Bras Dermatol. 2013; 88(2):306-8.

5. Sociedade Brasileira de Dermatologia. Consenso Brasileiro de Psoríase 2012: Guias de avaliação e tratamento. 2. ed. Rio de Janeiro: Sociedade Brasileira de Dermatologia; 2012. Available from: http://www. ufrgs.br/textecc/traducao/dermatologia/files/outros/Consenso_Psoriase_2012.pdf.

6. Winterfield LS, Menter A, Gordon K, Gottlieb A. Psoriasis treatment: current and emerging directed therapies. Ann Rheum Dis. 2005; 64(Suppl 2):ii87-90.

7. Singh RK, Lee KM, Jose MV, Nakamura M, Ucmak D, Farahnik B, et al. The patient's guide to psoriasis treatment. Part 1: UVB phototherapy. Dermatol Ther. 2016; 6(3):307-13.

8. Farahnik B, Nakamura M, Singh RK, Abrouk M, Zhu TH, Lee KM, et al. The patient's guide to psoriasis treatment. Part 2: PUVA phototherapy. Dermatol Ther. 2016; 6(3):315-24.

9. Duarte IAG, Cunha JAJ, Bedrikow RB, Lazzarini R. Qual é o tipo de fototerapia mais comumente indicada no tratamento da psoríase? UVB banda estreita e PUVA: comportamento da prescrição. An Bras Dermatol. 2009; 84(3):244-8

10. Lebwohl M, Ting PT, Koo JYM. Psoriasis treatment: traditional therapy. Ann Rheum Dis. 2005; 64():83-6.

11. Sampaio SAP, Rivitti EA. Dermatologia. 3. ed. São Paulo: Artes Médicas; 2008.

12. Habif TP. Dermatologia clínica: guia colorido para diagnóstico e tratamento. 5. ed. Rio de Janeiro: Elsevier; 2012.

13. Miazek N, Michalek I, Pawlowska-Kisiel M, Olszewska M, Rudnicka L. Pityriasis alba - Common disease, enigmatic entity: up-to-date review of the literature. Pediatr Dermatol. 2015; 32(6);786-91. 